\title{
The decision-making process between rationality and emotions
}

\author{
Letizia Alvino $^{1}$, Massimo Franco ${ }^{2}$ \\ ${ }^{1}$ University of Molise, Campobasso, Italy \\ University of Twente, Drienerlolaan 5, 7522 NB, Enschede, The Netherlands \\ ${ }^{2}$ University of Molise, Campobasso, Italy
}

\begin{abstract}
:
The decision-making process has been analyzed in several disciplines (economics, social sciences, humanities, etc.) with the aim of creating models to help decision-makers in strategy formulation. The Organizational theory takes into account both the decision-making process of individuals and groups of a company. Numerous models have been built, which include a wide range of psychological, environmental, hierarchical factors, all of which only account the notion of rationality. In time, such concept has come to be considered pragmatically unrealistic and unachievable. Emotions have recently acquired an increasingly significant position (in the academic and economic society) as important component of the decision making-process. From this point of view neuroscience, the new branch of medical sciences could play a key role in studying individual decision-making processes. This article suggests that thanks to neuroscience it is possible to overcome current limitations in economics studies, for individual's choices, which are exclusively based on the rational component.
\end{abstract}

Keywords: Decision making; Groups; Rationality; Emotion; Neuroscience; Neuroeconomics

\section{Introduction}

The present paper analyzes the decisional process in the Organizational Theory. Until now, the decision-making process - either as individual or as group of individuals - has been mainly studied as a rational procedure, which presupposes the attainment of the best result by maximizing the decision maker's utility. In other words, the behaviors and the final outcome are dictated in advance by rationality.

Unfortunately, this theoretical approach has failed since rationality, be it absolute or bounded, is too utopian to account for the complexity of the decision-making process.

Firstly, the present paper tries to explain the main differences in decision making between individuals and groups.

Secondly, particular attention is addressed to the contribution of emotion in the individual decisionmaking process, analyzing both the physiological and physiognomical aspects.

The last paragraph illustrates new methodology that can determine the cerebral areas involved in the individual decision-making process. The paper draws a parallel between behavioral economics and neuroscience techniques.
The conclusions report a future research perspective for inferring individual and group decision-making processes.

\section{Methodology}

The bibliographic research was conducted only on peer-reviewed academic articles and books. To access to the content of the articles, two different and main platforms were used: Scopus and ScienceDirect. The research can be divided in two main steps. In the first, the papers were selected using keywords: decision-making process, organizational theory and emotion. Since no relevant results were found, we searched for other keywords: decision-making process and organizational theory. The articles were selected on the basis of the "title" and the "abstract". However, books were mainly used. In the second step, the research focused on physiological and neurological aspects of emotions on decisionmaking processes. Only peer-reviewed academic articles and books were examined. The literature analyzed were originated from journals belonging to several domains: Organizational behaviors and decision-making (Journal of Behavioral Decision 


\section{DOI: 10.18535/ijsrm/v5i9.18}

Making, Journal of Consumer Research, Judgment and Decision Making, Organizational Behavior and Human Decision Processes, Organizational Behavior and Human Performance, European Journal of Operational Research), Neuroscience (Annual Reviews of Neuroscience, Behavioral Neuroscience, Brain and Cognition, Celebral Cortex, Cognition, Nature, Nature Neuroscience, Trends in Cognitive Sciences), Psychology (Journal of Consumer Psychology, International Journal of Psychophysiology, Italian Journal of Psychopathology, Psychological Review, Psychological Science, Developmental Psychology, Journal of Economic Psychology, Journal of Personality and Social Psychology, Psychophysiology), Other (European Neuropsychopharmacology, Social Science Information).

\section{Decision-making processes}

Decision-making is nothing but a process through which it is possible to make a decision (Padoa Schioppa 2007). The term 'decision' [from Latin. decisio-onis, past participle of the verb 'decidere': decisus] means "to cut off, to end something" and it clearly expresses the will to resolve or to end a problem (Dizionario delle Scienze Fisiche 1996; March 1994). In particular, Kreitner and Kinicki (2008) explain that decision-making is based on finding and choosing alternative options to get to an ideal situation, which is the solution.

Everyone, be it individuals or organizations in society, must make more or less complex decisions on a daily basis. Making a decision may entail trivial issues, such as choosing where to have lunch, as well as more complex situations like buying a house, accepting or refusing a job, listing one's own company in the stock market or choosing the right logo for your brand. The objective of decision-making is generally to improve an individual or organization's condition based on one or more criteria (Caramia, Dell'Olmo 2006). It is not easy to realize which could be the best choice, the most beneficial or least detrimental one. It is even more complex to establish the process that leads to what is considered the best solution.

The notion of decision has been widely debated and analyzed in economics. An organizational decision is a process to identify and solve problems (Daft 2010). This process envisages two key stages: the first entails problem identification, while, the second, information on environmental and organizational conditions is monitored to establish whether performances are satisfactory or not, and to find the causes for inadequacy (Daft 2010).

In the problem-solving stage, the possible alternatives for actions are assessed, and then one of them is chosen and realized (Daft 2010). Furthermore, the decision-making process can also be analyzed based on the problem's complexity. A decision-maker who only considers one side of the issue is extremely different from another one who contemplates multiple aspects (Payne 1976). The set of objectives held by an actor in a variety of decision-making areas is the result of past sedimented learning experiences. One of the dividing criteria to choose among multiple decision-making strategies is the extent to which goals are either clear, or are to be verified and acquired in order to make a given decision (Grandori 1955). Research processes are considered decision-making sub-processes, whereas research criteria considering multiple alternatives are also extremely powerful in regulating the range of the research process.

Unfortunately, apart from objectives, the identification of problems and the processing of available information are not linear procedures, because of a series of factors. For instance, the absence or lack of information seriously hinders the decision-making process; without a solid foundation for one's own choices, it is impossible to make decisions. Information overload also hampers decision-making, as decision makers have to select relevant information among a wide variety of valid data. They also have to find the reason (be it technical, economical, emotional, etc.) for choosing it, with relation to their problems and goals. Indeed, the outcomes of the decision-making process are affected by a set of elements and components such as problems, goals, alternatives, choice, research criteria and learning (Grandori 1955).

The notion of decision in business economics is not a uniform one; it rather acquires differing characteristics depending on (i) the context in which decisions are made, (ii) the role played by the decision maker and (iii) the number of decision makers who are involved in the process. Two different types of decision-making can be identified: individual and group ones. Individual decision-making is one of the greatest 


\section{DOI: $10.18535 /$ ijsrm/v5i9.18}

responsibilities for managers (Kreitner, Kinicki 2008). In organizational decision-making, a decision has to be implemented both at individual and group level in order to be effective. It is not enough for managers to have a bright idea, as they also must be able to persuade their team or decision-making bodies and to demonstrate that their choices are feasible. In this case, on the one side decisions directly affect individual's career opportunities, benefits and professional satisfaction; while, on the other, managerial decisions contribute to an organization's success or failure (Kreitner, Kinicki 2008).

Nowadays, the development of decision-making skills has become a key issue for any organization willing to increase its efficiency and the performance perceived by its customers (Marchello 2003). In various strands of business economics theory, business decisions have been studied to analyze the outcomes of economic choices and the decision-making process determining them (De Vecchi, Grandori 1983).

\section{The difference between individual and group decision-making processes}

In individual processes, it is a single person who has to make a decision. As we will explain below (see paragraph 2), theoretically speaking, the decision-making process can be easily divided into stages, which can be perfectly described. For each stage, the decision maker can establish goals, identify the problem, and make the best decision. This is an approach of the rational kind. However, decision-making is actually influenced by multiple factors, which are related to the individual's personality and to the external environment, both of which distort the perception of the problem and lead to solutions, which may not always be ideal (appropriate). Among the intrinsic variables depending on an individual's way of being, the notion of personality plays a significant role. It is defined as a relatively stable set of personal psychological characteristics, a durable model of individual psychological features, which account for an individual's uniqueness and influence the way a person interacts with others and with the environment (Tosi et al. 2002). Values, opinions, and attitudes are other personal factors, which affect decisions. According to Kluckhohn (1951), a value is a desirable, implicit or explicit, conception which characterizes an individual or a group and that influences actions through the selection of available methods, means and objectives. Opinions are concepts developed by a person with relation to a given event, while attitudes are the predisposition to behave positively or negatively when a given event occurs. Opinions and attitudes impact on the implementation phase and on alternatives' evaluation (Kluckhohn1951).

In the "stakeholder theory", when a manager and/or an entrepreneur make their decisions and behave in a certain way, they have to take into consideration all the internal and external groups which hold an interest and a strong influence (Freeman 2010). For this reason, when studying decision-making processes in the organizational theory it is not possible to take into account group decision-making processes.

In response to growing demands for efficiency and flexibility, organizations shift from individual to group-based structures (Franco et al. 2011). The notion of group is extremely wide and can apply to a family, a group of students, a jury, a committee, a consortium, a task force, a projectbased team, or a panel of experts who jointly carry out assessment. According to Davenport (1999), the most famous and common definition of group is "a collection of two or more interacting individuals with a stable pattern of relationships between them who share common goals and who perceive themselves as being a group".

Groups bring assets, adding knowledge and creativity, increasing the understanding and acceptance of ideas (Tosi et al. 2000). Numerous studies have shown the benefits for groups that engage in information exchange and communication within the information group (Keller, Staelin 1987; Gruenfeld et al. 1996; Rulke, Galaskiewicz 2000). Groups can actually reach a wider knowledge and provide different points of view, thus generating a wider understanding of problems and increasing the possibility for a decision to be accepted through goal sharing (Tosi et al. 2002; Kreitner, Kinicki 2008). A group can enhance creativity, which is another key element for an organization's success. The distinctive feature of group decision-making processes is the presence of a comprehensive communication network, where all the members can frequently communicate among one another (Grandori 1955).

When decisions are made without taking into any consideration awareness, the number of decision 


\section{DOI: 10.18535/ijsrm/v5i9.18}

makers and the context, they produce outcomes (positive or negative) that most of the times affect the environment they refer to. Many individual choices are banal, at least apparently, and, because of this, are often made very quickly. Still the consequences of trivial decisions may accumulate and result into catastrophic effects (Tosi et al. 2002). The problem with decisions is the choice of a pathway that leads a system, an individual, or an organization from an initial stage to a final one (Feldman, Kanter 1965).

\subsection{Issues in individual and group decision- making processes}

An erroneous evaluation may cause difficulties when defining the problem or the goals (Tosi et al. 2002). For example, managers who place a great value on their ideas tend to discard a priori any advice coming from the outside, thus losing contact with the key point, which is solving the problem. All these features influence the way in which an individual interacts, relates to the problem and comes to the solution. Apart from individual values, the decision-making is also affected by the context in which the decision makers are and play their roles. Tosi et al. (2002) claim that the external environment, which includes all the elements that are present in the individuals' external world, can interact with them and influence their behavior. Individuals live in social systems where they play specific roles associated with age, sex and social positioning (March 1994). For this reason, the decisionmaking is influenced by the role played by a subject within an organization or a social context. March (1994) states that decisions are shaped by the roles played by decision makers: within their family, their school or organization. Individuals learn what it means to be a mother, a manager, a student or a man. Once subjects identify with a given status quo, they tend to make decisions in connection with it and bound by it. Quite oppositely, the decision-making process is dynamic and it urges decision makers to make continuous changes and stimulates them to adjust to the external environment with a comprehensive understanding of the problem, irrespective of any status quo. The combination between the way individuals perceive and comprehend stimuli and the way they choose to respond to that information is termed decision style (Kreitner, Kinicki 2008).
Just like what happens for the individual ones, also for group decisions it is not possible to identify an objectively verifiable response or a performance, which is much better than another one. It is rather the groups' task to choose among various alternatives, and each of them may be perceived as beneficial at an individual level. (Brown 1989). However, the activation of group decision-making processes entails both advantages and disadvantages (Maier 1967), which mostly depend on the intrinsic features of teamwork, on the conditions for effective group work and on the team leadership's characteristics (Tosi et al. 2002). In order to maximize group decision making, it is advisable to have an environment where (i) each group member feels at ease and free to express their opinions (Kreitner, Kinicki 2008), and where (ii) information and skills held by each member are quite similar in terms of consistency and relevance to the problem. In this way, each member's capacity to influence the group is balanced (Grandori 1955). In case these elements are missing, there is a failure in the decision-making process and pathologies arise within the group. Conformism, which is the fear of disagreement and intolerance to deviance, is a disadvantage, which stems specifically from group decision making (Tosi et al. 2002). In addition, Janis (1972) uses the term "groupthink", a phenomenon which occurs when the need for consensus and cohesion is more important than making the right or more correct choice. A 'risky shift', or 'polar shift', is also found in group decision making (Brown 1990). Group members consistently make more cautious or conservative choices than individuals (Stoner 1968, Fraser et al. 1971). With 'polarization', a group's decision is the most extreme decision in the average individual opinions, which follow the same trend (Brown 1990) as a result of a mutual cognitive reinforcement (Grandori 1955).

\section{Types of rationality in the main theories of decision making processes}

It is impossible to conceive of the concept of decision making without also considering the notion of rationality. Therefore, in order to analyze the issues that generally occur in individual and organizational decision-making processes, it is necessary to propose an interpretation of the notion of rationality. Studying the logic of decision making also entails 


\section{DOI: $10.18535 /$ ijsrm/v5i9.18}

identifying the levels of rationality which can be found in individuals and in their behaviors, objectives, evaluations and in their very same final choices (Sciarelli 1996).

In the course of time, the term 'rational' has come to acquire several different meanings. In the common sense, it is associated with what is 'intelligent' or 'effective', while in other cases it means 'primly materialistic' or even 'sane' (March 1994). In business economics, rationality connotes homo oeconomicus (Mill 1848), a person whose main characteristics are rationality and an exclusive care for their own individual interests. This appears to be a simplification of the complex human reality, which considers the subject of economics to be an abstract individual, whose behavior in a complex social reality is perceived to be moved exclusively by economical motives, aiming for wealth maximization (Treccani 2014). The rational approach to individual decision making emphasizes the need for a systemic analysis of the problem, followed by choice and realization, moving along a precise logic sequence (Daft 2010).

For this reason, the notion of rationality is closely related to models and theories. The models available for the decision-making process have been selected and analyzed to devise four comparable types of strategies adoptable by businesses (De Vecchi, Grandori 1983). In this work, the four main models will be considered: the normative decision-making, the heuristic, the ex-post rationality model, the intuitive model.

The normative decision-making model is rational, since it assumes that decision makers use a set of rational criteria while making a decision, which is also considered rational. This model aims for optimization, by maximizing the decision maker's utility functions (Tosi et al. 2002). Rational choice theories assume that decision-making processes are consequential, since action depends on expectations of future effects; and preferencebased, given that consequences are assessed based on individual preferences (March 1990). The notion of absolute rationality is supposed to lead an organization to adequate consistency between aims and goals, by defining unambiguous goals, which are adequate for the situation, and the aim, within a controllable external environment in the long term (Ferrando 1981). Thanks to this model, no interpretive subjectivity is possible, while a predetermined sequentially of decision-making processes is established, based on a calculated rationality capable of optimizing choices. It is apparent that such a model is purely theoretical and does not have any practical application. No behavior or decision can be considered rational in the absolute sense, since people have to be evaluated against the specific set of values held by the individual who finally makes the choice (Sciarelli 1996). For this reason, Simon (1957) has devised a heuristic model based on the assumption that it is impossible to define what rationality is in a clear and univocal way, without specifying the value system to be used to assess it. Studies on actual decision making-processes suggest that not all the possible alternatives are known, not all the consequences can be taken into consideration and not all the preferences can be defined (March 1998). The heuristic model is based on the notion of bounded rationality, which assumes that human abilities are fallible and constrained, and information is not perfect (Tosi et al. 2002).

Quite differently from the normative decisionmaking model, decision makers do not refer to a complete and coherent set of preferences, but rather appear to set incomplete and incoherent goals, all of which cannot be completely considered at the same time (March 1998). Compared to the rational model, Simon's normative one shows that the rational procedure is characterized by limited processing of information, the use of heuristics (practical rules or precautions to diminish the need for processing information) and the choice of satisfactory solutions (Kreitner, Kinicki 2008). Instead of calculating the 'best possible action', decision makers aim at taking an action which is 'good enough' (March 1998). The idea of bounded rationality is now acknowledged in most individual decision-making theories (March 1998).

The "garbage can" theory was devised by Cohen, March and Olsen (1972), and Tosi et al. (2002) define it as an ex-post rationality model, where rationality shows after the decision is made. This model is different from the ones mentioned above since it does not take into account a single decision, but it rather focuses on the management of multiple decision-making processes. These decisions are made in contexts defined as 'organized anarchies' with high levels of uncertainty (Macinati 2012). In this model, multiple decision makers are involved in the 


\section{DOI: $10.18535 /$ ijsrm/v5i9.18}

process in a limited manner, or rather their involvement depends on their individual needs, goals and means. This model considers the fact that different decision makers hold differing interests and values and are subject to cognitive distortion (as explained in para. 1.1) (Tosi et al. 2002). In this model, decision making is considered as the result of a fortuitous and accidental process, originated by autonomous events totally lacking any logical sequence. The absence of order in decision-making stems from complex decision-making processes and unknown variables (Macinati 2012).

According to Macinati (2012), decision making is not divided into different stages and it does not envisage the identification of objectives or of solutions to eventual problems, but it rather is a combination of potential solutions, participants and possibility to choose.

Decisions can be made through an intuitive or reasoned process or a combination of the two. In intuitive processes, when a decision is formulated, experience and judgment prevail over sequential logic or explicit reasoning (Daft 2010). This is an unconscious process, which is determined by forms of tacit experience and, for this reason is often associated with an approach of bounded rationality (Tosi et al. 2002). Some scholars consider intuition as a sort of extrasensory power, a sixth sense, while others see it as a personality trait (Tosi et al. 2002; Behling, Eckel 1991). Intuition is not generally arbitrary since it does not oppose rationality, as it is commonly thought, but it rather acts in complementary ways and it is originated by a long-time experience, which is often kept safe in the subconscious (Daft 2010; Simon 1987). This model has its practical application in the short term and particularly in troubled environments with a high level of uncertainty when sudden changes in the conditions require timely decisions without the possibility to resort to previous similar cases (Gambel 2010; Tosi et al. 2002). In case of a high degree of complexity or ambiguity, previous experience and judgment can help to identify both problems and solutions. Extensive use of the intuitive model is encouraged in psychology and organization sciences.

\section{The concept of emotion}

According to Macinati (2012), a model is a simplified representation of reality and of the variables, which are considered to be significant in trying to explain the phenomenon under analysis. Gambel (2010) states that the models which have been devised by literature are not mutually exclusive, since some of them share the same explicative variables, even though they come up with differing representations of decision-making processes. These theoretical representations of reality tend to consider some variables while discarding others and reproduce only part of the factors that are actually involved in decision making. As it can be easily concluded from the previous analysis, all these models systematically exclude the concept of emotion, while focusing on the notion of rationality, even if it is sometimes considered as bounded. Simon had already foreseen that his theory would have been incomplete until the role of emotions is not acknowledged. Even scholars such as Kahneman and Tevrsky (1979), with a psychological background, chose to focus on the comprehension of cognitive processes, rather than on emotions. Quite apparently, in the twentieth century, no model has included emotions in the study of decision making processes. Only recently has the concept of emotion been studied in connection with decision making processes, while according to Lerner et al. (2014), the amount of scholarly papers on this subject doubled between 2004 and 2007 and from 2007 to 2011.

Because of a dual notion of the human being, which entails the superiority of the rational element, the mind, over the irrational part, which is the emotional side; emotions have never been considered as an acceptable object of study and scientific enquiry (Cattarinussi 2006; Meneghini 2002). As Tiberi (1979) points out, emotions are viewed as an impediment for orderly and rational behaviors. In addition, Otnes and Beltramini (1996) claim that contemporary individuals often consider emotions as annoying or shameful, as weaknesses or useless instincts which should be restrained. The fact that only recently emotions have started to be studied also adds to the lack of clarity, which still nowadays impinges on many aspects of the subject matter (Meneghini 2002). An initial interest in emotions as a subject matter can be dated back to the 1960s, owing to progress in the field of psychology. In particular, emotions became the main object of research and study in psychoanalysis, which assumed it as a basic element of personality (Cattarinussi 2006). 


\section{DOI: 10.18535/ijsrm/v5i9.18}

Cognitivists, in particular, follow different approaches in the interpretation of the relationship between cognitive and emotional functions. In the first top-down perspective emotions are derived from a cognitive process, from learning, in the first place, about life events (Leventhal, Everhart 1979). Therefore, cognitive activities contribute to determine emotional experiences. In the second perspective, opposing the top-down one, emotions are viewed as capable of modifying the organization of cognitive processes (Cazzullo 1999). At the beginning of the 1980s, biologists, sociologists and ethologists also supported the renewed interest in emotions (Cattarinussi 2006). In those years a new discipline was born: affective neuroscience (Meneghini 2002), since it seemed necessary to find an answer to the new question on which neural structures are involved in emotional activities (Meneghini 2002). Neuroscientists such as LeDoux (1998) decided to investigate the phenomenon's physiological correlations, to answer questions on what cerebral mechanics underlie emotions such as fear, rage, joy, etc.

In order to understand the recent developments on this topic, it seems necessary here to define what an emotion is. Its origins can be dated back to modern psychology, which classifies various psychic impressions in the emotional sphere by using different terms such as emotions, affection, sentiment, passion, etc. In the semantic field, emotions just like affections and sentiments are all emotional expressions, but, quite differently from the others, emotions are characterized by a short duration (Wanderlingh 2008). Cattarinussi (2006) describes them as global, intense, short reactions of an organism, which occur when an unexpected situation triggers an action. According to Plutchik (1980), the term 'emotion' does not correspond to the phenomenological aspect, but rather to a complex reaction chain. Galati et al. (2008) state that emotions can be considered as psychobiological apparatuses that have evolved across time and through different species, to provide immediate responses to the problems and the opportunities we face in the environment. Emotions are nothing but an internal process triggered by an event-stimulus which is relevant for an individual's interest (Treccani 2014).

Denzim (1983) defines emotions as a process with a beginning, a duration and an attenuation phase. Emotions make it possible to regulate the relations occurring between an individual and the natural and social environment. They prepare organisms to react to events that are relevant for their wellbeing and survival; threats and opportunities are thus faced by using behavioral strategies and plans and provoking significant mental and physiological changes, which are suitable to establish relations among such behavioral plans (Ekman 1992; Galati 1993; Plutchik 1994; Scherer et al. 2001). Particularly positive emotions signal the presence of favorable occasions in the environment and lead to the realization of behavioral plans to fully profit from them (Fredrickson 1998; Galati \& Sotgiu 2004, 2005). Negative emotions, instead, announce the presence of critical situations, judged as negative and unpleasant, which hinder the individual's achievement of objectives and behavioral plans, thus risking their psychophysical balance (Galati et al. 2008). The term 'emotion' generally means internal experiences which are described with various and shared linguistic expressions such as happiness, anxiety, sadness, contentment, rage and so on (Wanderlingh 2008). People, be it adults or children, are able to recognize, classify and describe emotions more or less correctly, although it is not so simple to describe them in a scientific manner (Meneghini 2002).

There exist different classifications of emotions in literature. Plutchik (1980), for example, distinguishes 8 types of primary emotions: fear, rage, sadness, acceptance, diffidence, anticipation and surprise, from which 84 secondary emotions derive. Primary emotions can be divided into four pairs, with each pair countering another one (Meneghini 2002). According to Izard (1991), there are 10 main emotions, which can be combined with other personality systems to create 336 additional emotions, also called 'secondary'. Russel (1980) defines 28 emotional tags grouped into four emotional quadrants outlined by two perpendicular axes. However, emotion identification in itself is not sufficient unless it is coupled with the analysis of biological and neurological effects produced by it. 
DOI: $10.18535 /$ ijsrm/v5i9.18

\begin{tabular}{|c|c|c|}
\hline \multicolumn{3}{|c|}{ A Selection of Lihts of "Rasic" Eraotions } \\
\hline Reference & Fundamental Fimotien & Baxis for teclantas \\
\hline Arrold (1960) & 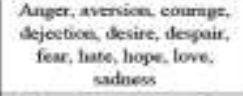 & Prelativo to nstion fendersia \\
\hline $\begin{array}{l}\text { Eknem, Fricean nod Ellwworh } \\
\qquad(1082)\end{array}$ & $\begin{array}{l}\text { Anger, dingunt, fear, jay. } \\
\text { salueus, uurprive }\end{array}$ & Utaivenal theis expressioes \\
\hline Findje (1086) & 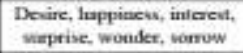 & Funme of nctice radiness \\
\hline Oray (1082) & $\begin{array}{l}\text { Rawe and teminc, anxiety, } \\
\text { joy }\end{array}$ & Hantwired \\
\hline Lard (t971) & 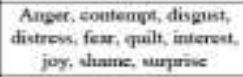 & Handwined \\
\hline Jame (1884) & Fear, prief, lave, rape & Bodily imvolvenent \\
\hline Medongall (1920) & 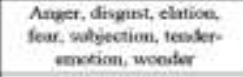 & Helative to besinats \\
\hline Mowre (1960) & Pain, plaswurk & Unicarned enobionel states \\
\hline $\begin{array}{l}\text { Onilley and Jolumon-Laird } \\
\text { (1987) }\end{array}$ & $\begin{array}{l}\text { Anper, dispust, meviety. } \\
\text { liespiness, sadoess }\end{array}$ & $\begin{array}{l}\text { Do not require propositiond } \\
\text { eontent }\end{array}$ \\
\hline Pubecpp (1982) & $\begin{array}{l}\text { Expestancy, fear, moe, } \\
\text { panic }\end{array}$ & Hartwired \\
\hline Plutchik (1980) & 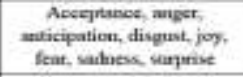 & $\begin{array}{l}\text { Pelation to adaptive biological } \\
\text { provesses. }\end{array}$ \\
\hline Toention (1984) & 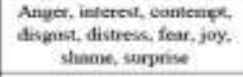 & Density of nevent firing \\
\hline Wastoen $(1930)$ & Feer, lowe, mase & Hardwined \\
\hline Weinet asd Gralumen (1984) & Hinppisiess, thidoeses & Atreributicat independent \\
\hline
\end{tabular}

Figure 1 List of "Basic" Emotions

\subsection{Physiological and physiognomical aspects of emotions}

An emotional reaction can produce physiological responses, which are related to the autonomic nervous system (Scherer 2005). The presence of an emotion is accompanied by neurophysiological aspects (peripheral responses regulated by the autonomic nervous system, hormonal and electrocortical reactions) and motor-expressive ones (posture and body movements, voice emissions) (Izard 1977).

Emotional responses can be collected based on verbal and nonverbal indicators. Through language, it is possible to communicate, to reflect, and to name an emotional experience, although it is rare that a person can directly define emotions. Nonverbal indicators, such as facial expressions and/or body movements, can make this function observable (Wanderlingh 2008). Expressions, by definition, can be observed from outside and they may originate from individuals' needs to express their emotions to others (Elster 2001). As a matter of fact, nonverbal communication can be considered as a relational language, since it can signal significant changes in interpersonal relations, sometimes without the very same individuals being aware of it (Russo 2015). Ekman and Friesen's Neurocultural Theory (1971) posits the existence of universal facial expressions and define it as a 'program' written in all the human beings' nervous system, these manifestations connect specific muscular movements to particular, determined emotions. Universality refers to the fact that these movements are associated with the same emotions in all the peoples, due to a mechanism of genetic heredity and it is excluded that they can be acquired so that they have different affective meanings based on culture (Russo 2015). Rather, this theory focuses on the cross-cultural differences, which affect these emissions, for example, based on social classes, groups of different ages and gender or individuals with different personality traits. In any case, Elster (2001) claims that emotions such as fear, happiness, anger, joy, sadness and other equally important ones are systematically associated with certain facial expressions, while this is not true for more complex emotions. According to Boucher and Ekman (1975), facial movements associated with emotions are to be found in three facial areas: brows - forehead, eyes - eyelids - bridge of nose, cheeks-nose-mouth-chin-jaw.

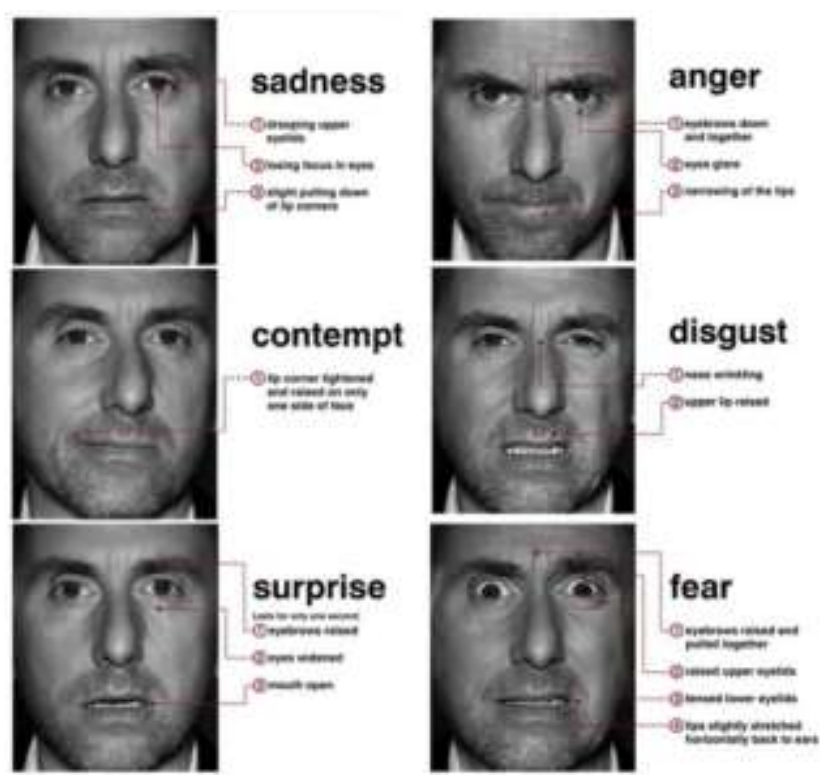

Figure 2 Facial expressions as nonverbal indicators of emotions

Apart from facial mimicry, other physiological patterns can signal emotional activation such as perspiration, accelerated or decelerated heart rate, changes in voice modulation, redness, frequent swallowing (Russo 2015). To some extent, distinct emotions can correspond to distinct activation configurations (Elter 2001). A high- 


\section{DOI: 10.18535/ijsrm/v5i9.18}

pitched voice can be observed in case of negative emotions, such as rage and/or fear, while a lowerpitch can be registered in case of sadness (Russo 2015). As Leverson et al. claim (1990), anger, fear or sadness are associated with an accelerated heart rate, while in case of disgust the heart rate slows down. Redness appears with embarrassment, shame or sexual arousal (Russo 2015), while frequent swallowing occurs in case of emotional activation and is not associated with any specific emotion.

Concerning neurophysiological aspects, it is necessary to introduce the concept of arousal. Activation or aurousal is a neurophysiological process with different degrees of intensity and it can be measured by observing variations in the brain's economic activity, in the heartbeat, through the presence or absence of perspiration and with changes in the skin's electrical conductivity (Meneghini et al. 1988). Cacioppo et. al 1996 define arousal as "a physiological, unconscious process". This differs from the viewpoint that arousal is a subjective experience of energy mobilization and can be measured solely from self-reports (Di Muro, Murray 2012). Although not all the scholars agree on the fact that the formation of an emotion involves the same cognitive structures, arousal is considered a key element for the appearance of affective states (Meneghini 2002). Emotional arousal acts in tandem and synergistically with the cognitive system. Different activation configurations can correspond to distinct emotions (Cazzullo 1999). Tiberi (1990) identifies two types of arousal: tout court and specific. The first one corresponds to the kind of activation, which the brain needs to live and act, which is ensured by specific arousals, including the emotional one (Meneghini 2002).

According to Mandler (1975), the activation of the autonomic system is not specific and it has to be connected to appraisal, which is the positive or negative evaluation of the stimulus by a subject while experiencing emotion. Emotions thus derive from the interruption of behaviors or cognitive processes. Such suspension determines the emotional tone, while the analysis of the meaning produces the quality of the emotional stimulus. Izard (1991), instead, believes that there exist more arousals that are specific, each associated with an emotion, and it is not necessary for cognitive processes to intervene in order to differentiate emotions.
Tucker et al. (1984) either asserts that affective arousal - in its positive or negative tonality triggers or inhibits memory to access positive or negative events. As Cazzullo et al. (1999) explain, a specific emotional state can mark different personal experiences even at a cognitive level. Robbins (1997) states that "Physiological arousal is not a specific process that can be reduced to the activation of one specific neural pathway but, rather, affects several neural pathways that ultimately influence the vigor and direction of attention to what the perceiver considers emotionally significant in the environment". Therefore, arousal involves neuronal and cognitive processes, although it is not possible to make a clear distinction between these two types of processes or to establish precisely the cerebral area involved in emotion activation. Emotional responses generate a disposition to action by engaging several nervous circuits, which lead to modifications in the arousal status of the brain and other systems in the organism (Giusti et al. 2013). Within these processes, the amygdala, the anterior cingulate cortex (ACC) and the orbitofrontal cortex play a key role in giving emotional meaning to information coming from outside. In addition, there are specific selection centers in the thalamus, which determine cognitive and subjective perception of emotions (Wanderlingh 2008). In the posterior hypothalamus, Bard (1929) identifies an emotiongenerating nucleus, which functions as an emotional regulator. As Plassman et al. (2012) explain: "One problem with using a given brain activation (the striatum) to infer a mental process (e.g., pleasure) is the proposed one to one relationship between the brain activity and the mental process of interest. Such a "reversed inference" is problematic because one brain area is usually involved in more than one mental process".

Although it is not easy to relate a specific cerebral area to a mental process, it is almost possible to do the opposite. It thus seems that emotions are able to modify the physical and psychological nature of human beings (Barrett et al. 2006). The activation of an emotional process causes first of all bodily reactions, most of which cannot be controlled, and changes in the brain's arousal status. These reactions result from a complex stimulus-response mechanism, which originates in the individuals' cerebral activity (Barrett et al. 2006). 


\section{DOI: $10.18535 /$ ijsrm/v5i9.18}

These emotional responses consequently affect both on the neuronal level, as they modify the cerebral neurotransmitters and especially the dopaminergic system, and on the psychological one, related to the way individuals interpret and react to these stimuli (Barrett et al. 2006).

The greatest difficulty in the study of emotions is determining the way in which they are activated (Tiberi 1988). It is not simple to establish the brain area in which emotional activity is originated, since it depends on a set of functions that are broadly disseminated in different cerebral regions. For this reason, it is not possible to make a clear-cut distinction between emotion-based cerebral areas and cognition-based ones. Furthermore, there are no visible signs that prove the existence of a single unified system for emotions (Dagleish 2004; Gazzaniga 2004; LeDoux 2000).

The left frontal areas seem to be correlated with a positive emotional tonality, associated with the propensity to approach an object, whereas the right frontal ones are related to a negative tonality, with reactions such as avoidance and regret (Fox Davidson 1987). Cazzullo et al. (1999) advance that the right hemisphere has a functional peculiarity with regard to emotion processing. However, once it has been processed, a different hemisphere is involved depending on the emotion's positive or negative quality.

Other studies have shown that the cerebral region, which is most commonly related to emotions, is the amygdala (Seymour, Dolan 2008). As a matter of fact, McGaugh (2000) points out that "research on emotion and memory shows that the hippocampus is necessary for memory storage however in presence of a highly emotional and arousing event, the amygdala modulates hippocampal storage processes to help ensure that the memory is retained". Equally, during emotional events, the amygdala modulates the visual cortex to guarantee that these events receive priority in perception and attention (Anderson, Phelps 2001; Vuilleumier et al. 2004). Conversely, shifting one's reasoning or appraisal of an emotional event can alter the emotional reaction to that event, which relies on the prefrontal cortex's modulation of the amygdala (Ochsner, Gross 2005). Furthermore, the amygdala is capable of modifying the way of thinking since the immediate emotional responses, such as fear, disgust or anger, will affect the processing of future information, taking into consideration the negative stimuli, which may be either real or just perceived as such (Giusti, Azzi 2013). Recent studies performed both on animals and human beings have highlighted the importance of the amygdala when considering the guiding choices (Seymour, Dolan 2008).

\section{Neuroeconomics}

Literature analysis shows that emotions have been studied to determine the cerebral areas they manifest themselves and their degree of influence over the decision-making process. However, despite the fact that since the 2000s there has been a growing interest in the topic, literature review has highlighted that there is still a lack of knowledge about the effects of emotions on decision-making processes.

To be thorough, numerous studies carried out by several research teams on decision-making in patients who can no longer process emotional information normally suggest that people make judgments not only by evaluating the consequences and their probability of occurring, but also and even sometimes primarily at a gut or emotional level (Bechara 2004). After damage, they develop difficulties in planning their workday and future; difficulties in choosing friends, partners, and activities (Bechara et al. 2000; Bechara et al. 2002). From a neurological perspective, the outcome of the decision-making process, which is the choice of an alternative, must be interpreted as the result of an interaction of the neural activity occurring among different subsystems, governed by diverse principles and parameters. According to Poletti (2007), the Orbitofrontal Cortex (OFC) is involved in the affective system for decision-making, whereas the Dorsolateral Prefrontal Cortex (DLPFC) and the frontal one participate in the deliberative system of the decision-making process. More generally, the Orbitomedial Cortex (OFC + Prefrontal Medial Cortex) can be considered as a convergence point for multisensory and emotional information, which plays a significant role in social relations and in the evaluation of meanings, as well as in the regulation of emotions (Giusti, Azzi 2013). This brain area, and particularly the right hemisphere, can monitor and regulate the body conditions, and consequently emotional states and socially adaptive behaviors. The Orbitomedial Cortex can be viewed as the 'place' 


\section{DOI: $10.18535 /$ ijsrm/v5i9.18}

where emotional signals are unconsciously represented, but that can still orient decision making (Giusti, Azzi 2013).

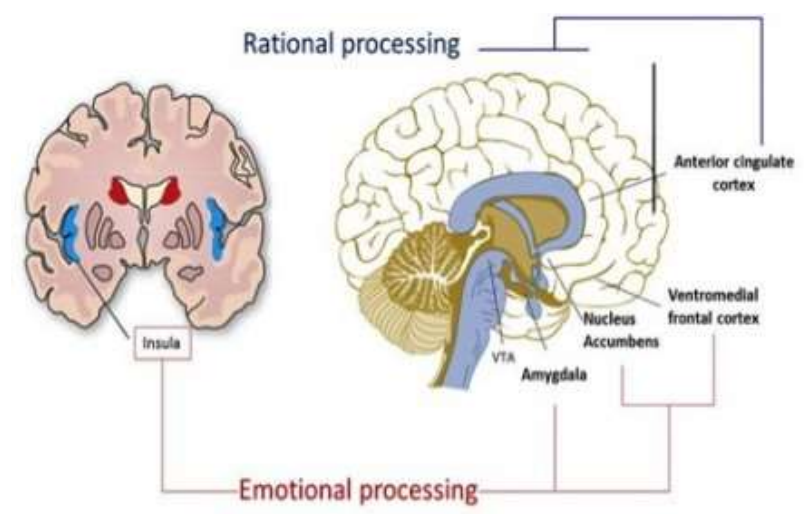

Figure 3 Rationality vs Emotions in the brain

The influence exerted by emotions on the decision-making process has been broadly studied by Damasio (1994). His team's following studies on patients with lesions in the prefrontal cortex propose a framework called "Somatic Marker Hypothesis" (Adolphs et al. 1999). This hypothesis was advanced to provide a valid neurological explanation for the everyday-life decision-making processes operated by patients suffering from lesions. Based on this theory, it is possible to trace a link between the patients' feeling and emotion anomalies and their inability to make decisions or evaluate real life events (Bechara et al. 2000, 2002). Damasio (1994) describes the process which employs biological information to affect and guide decision making based on previous similar experiences; such processes can bring both positive and negative results. During decision-making, somatic signals are activated, based on an automatic and intuitive emotional elaboration of the available information which helps an individual to choose a given alternative rather than another one (Adolphs et al. 1999; Poletti 2007). In these circumstances, making a decision stimulates a somatic response to mark future events, which are significant for the human being, by attributing to them a sense of danger or advantage. In this way, when a negative somatic marker is linked to a particular future outcome, an alarm signal is activated that tells us not to perform or to avoid that particular course of action (Valasquez 1998; Damasio 1994). Vice versa, when a positive somatic marker is linked, it becomes an incentive to make that particular choice (Valasquez 1998). This hypothesis shows the importance of the sensory mapping of visceral responses not only to understand feelings, but also in the execution of highly complex, goal-oriented behaviors (Bachara 2010).

All the studies conducted in this field have tried to demonstrate that emotions and decision making are closely connected. In neuroscience, an incidental affect is the way through which emotions can influence the decision making process. According to Glimcher and Fehr (2014), an incidental affect is a baseline affective state that is unrelated to the decision, but can, nevertheless, shift choices.

The great appeal of these studies has raised the attention among those economists who had been wondering whether or not classical economics and psychology, especially through the Game Theory, are able to account for the link between decisionmaking processes and human behavior.

In the last two decades, there has been a steady growth in the use of neuroscience in economics, with the use of fMRI and EEG to study economics-based decision-making processes. In 2000 McCabe coined the term Neuroeconomics, that is an interdisciplinary field including studies from neurosciences, economics and psychology. This research area deals with the neurobiology of decision making and the way it affects cognitive social interactions between humans and societies/economies. It studies how economic behaviors can pattern our understanding of the brain, and how neuroscientific discoveries can constrain and guide models of economics. While the standard economic hypothesis envisages that the decision making process is coherent with profit maximization (see paragraph 1), neuroeconomics asserts that choices are driven by a complex interaction of automatic processes (originated by most of the brain's electrochemical activity, that is its normal functioning) and controlled processes (activated in particular situations, normally when an individual has to face changes or has to make a decision to solve a problem) (Lowenstein et al. 2008). Not only does Neuroeconomics aim at understanding the mechanisms that drive decision-making processes, but also at studying (and in future also measuring) emotional factors that affect these processes.

Many studies in this field have focused on stress, which is a reaction to a situation in which the requests in an environment outnumber a person's resources and capacities to adjust to the situation. 


\section{DOI: $10.18535 /$ ijsrm/v5i9.18}

The induction of stress in the human body results in an increase in physiological arousal, in the levels of adrenaline and glucocorticoid release (Pettine, Cuppini 2009; Glimcher, Fehr 2014). Stress hormones are known to influence a number of brain regions related to emotions and decisions (Glimcher, Fehr 2014). Ungless et al. (2010) has shown how stress affects the dopaminergic neurons in the ventral tegmental area and the striatum. In particular, stress seems to impair the prefrontal cortex's (PFC) function and executive control, while enhancing the function of the amygdala (Hains, Arnsten 2008; Roozendaal et al. 2009). It is important to highlight that the physiological effects of acute stress extend after the event (Dickerson, Kemeny, 2004). As an example, adrenaline release is generally followed by a total discharge of energy surplus through more or less hostile behaviors, verbal aggressions against others or escape reactions (Pettine, Cuppini 2009).

Several studies have shown that stress impinges on the cerebral systems which are involved in the decision-making process so that it consequently affects choices made by an individual. One of the first studies was conducted by Porcelli and Delgado (2009) using the Cold-Pressor Task technique. The experiment aimed at analyzing the impact of acute stress on a financial decisionmaking process and investigating whether it has a positive or a negative influence on decisions (Porcelli, Delgado 2009). Participants were involved in games such as gain or loss domain, where players were supposed to choose between two potential wins or two potential losses (Glimcher, Fehr 2014). The experiment was first conducted under controlled conditions and secondly in a stressful situation. In order to produce high stress levels, participants were asked to immerse their hands in near-freezing water (4 ${ }^{\circ} \mathrm{C}$ ) for about 2 minutes (Porcelli, Delgado 2009). Under controlled conditions hands were immersed in room-temperature water $\left(25^{\circ} \mathrm{C}\right)$ for 2 minutes (Porcelli, Delgado 2009). The participants' choices showed a higher degree of reflection in case of stressful situations than under controlled conditions (Porcelli and Delgado 2009). There was a change in the use of the strategies (risky or conservative) employed by stressed participants (Glimcher, Fehr 2014). In this experiment, individuals who had undergone stress became more conservative in the gain domain game, and riskier in the loss domain one. In a similar study, psychologists Kahneman and Tversky (1979) obtained the same results even though this trend was amplified by exposure to stress.

Hall et al. (2010) have conducted a study, which associates risk propensity under stressful conditions with the participants' sex. For the experiment, the Balloon Analogue Risk Task (BART) was employed. Participants were asked to inflate a series of balloons on the screen. The larger a balloon got, the more points it was worth; but, in case the balloon exploded, the participants would receive no points. During the experiment, males who underwent acute stress were more predisposed to risk taking, while stressed females decreased their risk taking (Glimcher, Fehr 2014). Another stress-by-gender case was observed in studies, which used the Iowa Gamble Task (IGT). In the IGT, participants can choose between decks of cards that offer higher payoffs with greater chances of loss (risky) or low-payoff, low-risk (safe) decks (Glimcher, Fehr 2014). Males showed a tendency to pick cards from the risky decks after exposure to a social stressor, but this effect was not found in females (Preston et al. 2007; Van den Bos et al. 2009).

Stress and emotions in general bring great changes to the human beings' neural processes in such a way that they affect their actions and conception or vision of the external world. The potential of emotions to affect decision making stems from the fact that it is often the decision-making process itself that can be considered an emotional process. We tend to undertake elaborate decision making processes only for important decisions, but precisely in these cases emotional trade-off difficulty will occur (not so much for trivial decisions). Emotions are also present after we have decided. After having made a choice and before the outcomes are known we are often in a state between hope and fear. Sometimes we are eager to learn about the outcomes of our decision, expecting the best. Other times we avoid this information as we fear the worst (Shani \& Zeelenberg, 2007; Shani, Tykocinski \& Zeelenberg, 2008). When the outcomes materialize, they may again be a source of emotions, such as elation, happiness, surprise, regret and disappointment (Zeelenberg et al., 1998). These emotions influence the way human beings evaluate their choices and thus their way of acting. 


\section{DOI: $10.18535 /$ ijsrm/v5i9.18}

There are at least two respects in which the emergence of Neuroconomics promises to establish a scientific change. The first one concerns the scope of Neuroeconomics' proposed revolution. Economists, psychologists and neuroscientists have separately achieved significant successes in modeling and explaining choice behavior. However, they usually employ dissimilar constructs and pursue different explanatory goals (Glimcher, Fehr 2014). The pioneers of Neuroeconomics frequently manifest the ambition to develop a single, unified theory of choice behavior that spans Neuroeconomics's parent disciplines and "transcends the explanations available to neuroscientists, psychologists, and economists working alone" (Glimcher, Rustichini 2004). A second peculiarity of Neuroeconomics' intended revolution relates to its purported depth. The proponents of Neuroeconomics rarely rest content with integrating particular findings from economics, psychology and neuroscience.

\section{Conclusions}

The decision-making process is commonly studied in several disciplines such as economics, psychology, sociology and cognitive sciences. Unfortunately, questions on how this process is formulated and applied to human beings are still unanswered in economics.

This article provides a brief analysis of the models that have been devised to establish decision-making parameters, in order to make decision-making strategy planning easier for businesses. These models essentially aim at identifying and examining the exogenous and endogenous variables, which are usually present in decision making, as well as building a simplified archetype of reality. Such models are mostly based on the principle of rationality, which still nowadays is the basis of theories of economics, which totally exclude emotional components. It seems apparent that, in time, the principle of rationality has proved to be limited and not comprehensive enough to allow for the formulation of business organization theories and not only. Still nowadays, its limitations consist of its incapability to integrate and explain the concept of emotions in decision making, which however greatly influence the decision-making processes.
Literature analysis in this article shows the limitations of the current way individual decisionmaking processes are analyzed. It seems advisable here to move towards a holistic approach to research, in the way described by the Business Diction: "All-encompassing view based on the knowledge of the nature, functions, and properties of the components, their interactions, and their relationship to the whole." A holistic approach implies that studies have to be simultaneously planned, and carried out step-by-step by all the science branches involved. Holistic studies of economics and neuroscience will set up models that are more effective.

Neuroscience can give a great scientific and empirical contribution to morpho-functional aspects of the nervous system while economics can provide theoretical models. By analyzing the role of neurotransmitters and the anatomofunctional structure of the nervous system, it will be possible to identify a certain number of cerebral areas controlling the 'production' of emotions and to outline possible incidental affects. Neurosciences currently have a wide range of case studies available related to the amygdala, the OFC and the Orbitomedial cortex which are involved in the affective system of individual decision making, as well as other studies on the effects of stress on the human brain. The few results so far are in any case extremely interesting and open up new frontiers in Neuroeconomics.

It is easy to foresee that a long-term work programs will be necessary to achieve significant results in the decision-making process of individuals.

Neuroeconomics results will be universally recognized as sound, when future benefits will be reliably measured from the application of this methodology.

Once, these benefits will appear worldwide accepted, it will be necessary to move on a new frontier, to analyze the behavior of individuals when alone or when performing as a cluster. We think possible two alternatives: (i) individuate ordinary people, namely representative of each social group under investigation; scaling-up from successful results obtained on individuals to those related groups.

For example, researchers may investigate the function of mirror neurons to anticipate and predict individuals' choices during a negotiation, 


\section{DOI: 10.18535/ijsrm/v5i9.18}

competition, acquisition or a process of team building.

Since mirror neurons are types of brain cells that respond equally either when human being is performing an action or when witnessing someone else carrying out the same action.

\section{Acknowledgements.}

Authors are deeply grateful to Dr. Efthymios Constantinides, University of Twente, for his valuable comments and suggestions.

\section{Reference}

1. Adolphs, R., \& Russell, J. A. \& Tranel, D. (1999). A Role for the Human Amygdala in Recognizing Emotional Arousal From Unpleasant Stimuli. Psychological Science (http://pss.sagepub.com/), (10), 167-171. http://pss.sagepub.com/content/10/2/167

2. Anderson, A., \& Phelps, E. (2001). Lesions of the Human Amygdala Impair Enhanced Perception of Emotionally Salient Events. Nature, (411), 305-309. http://aclab.human.cornell.edu/publication s/papers/Anderson_Phelps_Nat01.pdf

3. Bard, P. (1929). The Central Representation of the Sympathetic System. Archives of Neurology and Psychiatry, (22), 230-246.

http://archneurpsyc.jamanetwork.com/artic le.aspx?articleid $=644298$

4. Barrett, L. F., \& Mesquita, B., \& Ochsner, K. N., \& Gross, J. J. (2006). The Experience of Emotion. Annual Review of Psychology, (58), 373-403.

http://www.ncbi.nlm.nih.gov/pmc/articles/ PMC1934613/

5. Bechara, A. (2004) The Role of Emotion in ecision-Making: Evidence from Neurological Patients with Orbitofrontal Damage, Brain and Cognition (http://www.journals.elsevier.com/brainand-cognition), (55), 30-40.

http://people.hss.caltech.edu/ steve/bechar a.pdf

6. Bechara, A., \& Damasio, H. \& Antonio R. Damasio (2000). Emotion, Decision Making and the Orbitofrontal Cortex. Celebral Cortex, (10), 295- 307. http://cercor.oxfordjournals.org/content/10 13/295.full.pdf+html
Future Neuroeconomics studies must focus on identifying exactly how this occurs (e.g., affecting the value function, the decision weight function, or some other mechanism).

7. Bechara, A., \& Tranel, D., \& Damasio, A. R. (2002). The Somatic Marker Hypothesis and Decision-Making, in Boller, F. \& Grafman, J. (eds.). Handbook of neuropsychology: Frontal lobes. Amsterdam: Elsevier.

8. Behling, O. \& Eckel, N. (1991). Making Sense Out of Intuition. Academy of Management Executive, (1), 46-54. http://amp.aom.org/content/5/1/46.short

9. Boucher, J. D., \& Ekman, P. (1975). Facial Areas and Emotional Information. Journal of Communication (http://www.jocm.us), (2), 21-29.

http://onlinelibrary.wiley.com/doi/10.1111 jj.1460-2466.1975.tb00577.x/full

10. Cacioppo, J. T., \& Bernston, G. G., \& Crites, S. L. (1996). Social Neuroscience: Principles of Psychophysiological Arousal and Response, in Social Psychology: Handbook of Basic Principles, Higgins, E. T. 6 Kruglanski A. W., New York: Guilford.

11. Caramia, M., \& Dell'Olmo, P. (2006). Decisione.

Treccani (http://www.treccani.it), VII appendice. http://www.treccani.it/enciclopedia/decisio ne_(Enciclopedia-Italiana)/

12. Castelli, I., \& Marchetti A. (2007) Teoria della Mente e Neuroeconomia: la Comprensione degli Stati Mentali nei Processi di Decision Making, in Pravettoni, G., \& Vago, G. (eds), Medical Decision Making. Decidere in Ambito Sanitario. Milan: McGraw-Hill.

13. Cattarinussi, B. (2006). Sentimenti, Passioni, Emozioni. Le Radici Del Comportamento Sociale. Milan: Franco Angeli.

14. Cazzullo, A. G., \& Musetti, M. C., Musetti, \& L., Bajo, S., \& Sacerdote, P., \& Panerai, A (1999). Beta-endorphin Levels in Peripheral Blood Mononuclear Cells and Long-Term Naltrexone Treatment in 


\section{DOI: $10.18535 /$ ijsrm/v5i9.18}

Autistic Children. European

Neuropsychopharmacology, (9), 361-363.

http://www.sciencedirect.com/science/artic le/pii/S0924977X99000103

15. Cohen, M. D., \& March, J. G., \& Olsen, J. P. (1972). A Garbage Can Model of Organizational Choice. Administrative Science Quarterly,(17), 1-25. http://www.jstor.org/stable/2392088?seq= 1\#page scan tab contents

16. Cuppini, G., \& Pettine, P. (2009). La fabbrica dello stress. De Qualitate, (8), 6874.

17. http://docplayer.it/16527497-La-fabbricadello-stress.html

18. Daft, R. L. (2010). Organizzazione Aziendale. Milan: Apogeo.

19. Dagleish, T. (2004). The Emotional Brain. Nature Review Neuroscience (http://www.nature.com/nrn/index.html), (5), 582-589. http://stanford.edu/ knutson/ans/dalgleish 04.pdf

20. Daft, R. L. (2010) Organization Theory and Design. Boston: Cengage Learning.

21. Damasio, A. R. (1994) Descartes' Error: Emotion Reason, and the Human Brain. New York: Avon Books.

22. Davenport, H. (1999) Groups and Teams, in Brook, S. I. (ed.). Organizational Behavior, London: Financial Times Pitman publishing.

23. De Vecchi, C, \& Grandori, A. (1983). I Processi Decisionali D'Impresa. La Scelta dei Sistemi Informativi. Milan: Giuffrè Editore.

24. Di Muro, F., \& Murray, K. B. (2012). An Arousal Regulation Explanation of Mood Effects on Consumer Choice. Journal of Consumer Research, (39), 574-584.

http://jcr.oxfordjournals.org/content/jcr/39/ 3/574.full.pdf

25. Ekman, P. (1992). Are there Basic Emotions?. Psychological Review

26. (http://www.apa.org/pubs/journals/rev/), (99), 550-553.

https://www.paulekman.com/wpcontent/uploads/2013/07/Are-There-BasicEmotions1.pdf

27. Ekman, P., \& Friesen, \& Wallace, V. (1971). Constants Across Cultures in the
Face and Emotion. Journal of Personality and Social Psychology, (2), 124-129.

https://www.paulekman.com/wp-

content/uploads/2013/07/Constants-

Across-Cultures-In-The-Face-AndEmotion.pdf

28. Elster, J. (2001). Sensazioni Forti. Emozioni, Razionalità e Dipendenza. Bologna: Il Mulino.

29. Fassio, O., \& Galati, D., \& Costa, T., 6 Sotgiu, I., \& Rognoni, E., \& Fazzari, M., \& Senatore, G. (2008). Psicofisiologia Della Vita Quotidiana: Proposta per un Metodo di Indagine Integrata degli Aspetti Fisiologici e Soggettivi della Vita Quotidiana, VIII Congresso Nazionale di Psicologia della Salute.

30. Feldman J., \& Kanter H. E. (1965). Organizational Decision Making, in March, J.G. (ed.). New York: Handbook of Organization.

31. Ferrando, M. G., (1981). Popular Sport and Sociocultural Change in the Spain of the 80's., in Gras, F., \& Benkert, G. (eds.). Physical culture and sports in the way of social groups 2 volumes, VII International Symposium of the International Committee for Sociology of Sport, ICSS) Vol. 2. Spain: Universidad Autonoma of Madrid.

32. Fox, N. A., \& Davidson, R. J. (1987). Electroencephalogram Asymmetry in Response to the Approach of a Stranger and Maternal Separation in 10-month-old Infants, Developmental Psychology, (23), 233-240.

http://psycnet.apa.org/index.cfm?fa=buy.o ptionToBuy\&id=1987-18307-001

33. Franco, M., \& Di Virgilio, F., \& Di Pietro, L., \& Camillo, A. (2011). Frameworks for a Consumer's Group Knowledge Representation in Pantano, E., \& Timmermans, H. (eds.), Advanced Technologies Management for Retailing: Frameworks and Cases. Hershey: IGI Global.

34. Fredrickson, B.L. (1998). What Good Are Positive Emotions?. Review of General Psychology, (2), 300-319.

35. http://www.ncbi.nlm.nih.gov/pmc/articles/ PMC3156001/ 
36. Freeman, E. R. (2010). Strategic Management: a Stakeholder Approach. New York: Cambridge University Press.

37. Fumagalli, R. (2011). Philosophical Foundations of Neuroeconomics Economics and the

38. Revolutionary Challenge from Neuroscience. London: The London School of Economics and Political Science (LSE)

39. Galati, D. (1993). Le Emozioni Primarie. Torino: Bollati Boringhieri.

40. Galati, D., \& Sotgiu, I. (2004). Happiness and Positive Emotions. Ricerche di Psicologia, (1), 41-59.

http://www.torrossa.com/resources/an/220 $\underline{5098}$

41. Galati, D., Sini, B., Tinti, C. \& Testa, S. (2008). The Lexicon of Emotion in the Neo-Latin Languages. Social Science Information, (47), 205-220.

http://ssi.sagepub.com/content/47/2/205.fu $\underline{\text { ll.pdf }+ \text { html }}$

42. Galati, G., \& Avenanti, A., \& Bueti, D., \&, \& Aglioti, S. M. (2005), Transcranial Magnetic Stimulation Highlights the Sensorimotor Side of Empathy for Pain. Nature Neuroscience, (8), 955-960. http://www.nature.com/neuro/journal/v8/n 7/abs/nn1481.html

43. Gambel, E. L. (2010). Management \& Organizzazione. Dai Protagonisti del Successo Aziendale alla Progettazione degli Organigrammi. Milan: Franco Angeli.

44. Gazzaniga, M. (2004). The Cognitive Neurosciences III Cambridge, Cambridge: MIT Press.

45. Giusti E., Azzi, L. (2013). Neuroscienze per la Psicoterapia. La Clinica dell'integrazione Trasformativa. Rome: Sovera Stumenti.

46. Glimcher, P. W., \& Rustichini, A. (2004). Neuroeconomics: The Consilience of Brain and Decision. Science, (306), 447452.

http://science.sciencemag.org/content/306/ 5695/447.full
47. Glimcher, P., Fehr, E. (2014). Neuroeconomics: Decision Making and the Brain. San Diego: Academic Press.

48. Grandori, A. (1955). L'organizzazione delle attività economiche. Bologna: Il Mulino.

49. Grandori, A., De Vecchi, C. (1983). I Processi Decisionali d'Impresa. La Scelta dei Sistemi Informativi. Milan: Giuffrè Editore.

50. Gruenfeld, D. H., \& Mannix, E. A., \& Williams, K. Y., \& Neale, M. A. (1996). Group Composition and Decision Making: How Member Familiarity and Information Distribution Affect Process and Performance. Organizational Behavior and Human Decision Processes, (1), 1-15. http://www.sciencedirect.com/science/artic le/pii/S0749597896900618

51. Guareschi, C. A., \& Lenti, C., \& Musetti, C., \& Musetti, L. (1995). Processi Mentali in Età Evolutiva. Modelli Neuropsicologici e Clinici. Milan: Franco Angeli.

52. Hall, L., \& Johansson, B., \& Tarning, B., \& Sikstrom S., \& Deutgen, T. (2010). Magic at the Marketplace: Choice Blindness for the Taste of Jam and the Smell of Tea. Cognition, (117), 54-61. http://www.lucs.lu.se/wpcontent/uploads/2011/01/Hall-et-al.-2010Magic-at-the-Marketplace-ChoiceBlindness-for-the-Taste-of-Jam-and-theSmell-of-Tea.pdf

53. Izard, C.E. (1977). Human Emotion. New York: Plenum Press.

54. Izard, C.E. (1991). The psychology of emotion. New York: Plenum Press.

55. Kahneman, D, \& Tversky, A (1979). Prospect theory: an Analysis of Decision under Risk. Econometrica, (47), 263- 291. http://www.jstor.org/stable/pdf/1914185.p df

56. Keller, K. L., \& Staelin R. (1987). Effects of Quality and Quantity of Information and Decision Effectiveness. The Journal of Consumer Research (http://www.ejcr.org), (14), 200-213. http://www.jstor.org/stable/2489411?seq= 1\#page_scan_tab_contents

57. Kluckhohn, C. K. (1951). Values and Value Orientations in the Theory of Action, in Parsons, T., \& Shils, E. A. 


\section{DOI: $10.18535 /$ ijsrm/v5i9.18}

(eds.). Toward a General Theory of Action. Cambridge: Harvard University Press.

58. Kreitner, R., Kinicki, A. (2008). Comportamento Organizzativo. Milan: Apogeo.

59. LeDoux, J. (1998). Il Cervello Emotivo. Milan: Baldini \& Castoldi.

60. LeDoux, J. E (2000). Emotion Circuits in the Brain. Annual Reviews of Neuroscience, (23), 155-184.

http://stanford.edu/ knutson/ans/ledoux00. pdf

61. Leventhal, H., \& Everhart, D. (1979). Emotion, Pain and Physical illness, in Izard, C. E. (ed). Emotions in Personality and Psychopathology. New York: Plenum Press.

62. Leverson, R., \& Ekman, P., \& Friesen, W.V. (1990). Voluntary Facial Action Generates Emotion Specific Automatic Nervous System Activity, Psychophysiology, (27), 363-384.

https://www.paulekman.com/wpcontent/uploads/2013/07/VoluntaryFacial-Action-Generates-EmotionSpecific-Autom.pdf

63. Macinati, M. (2012). Behavioral Management Accounting. La Dimensione Cognitiva e Motivazionale dei Sistemi di Controllo Direzionale. Milan: Franco Angeli.

64. Maier, N. (1967). Assets and Liabilities in Group Problem Solving: The Need for an Integrative Function. Psychological Review, (4), 239-249. http://faculty.fiu.edu/ revellk/pad3431/M AIER.pdf

65. Mandler, G. (1975). Mind and Emotion. Florida: Krieger Publishing Company.

66. March, J. G. (1998) Prendere Decisioni, Il Mulino, Bologna

67. Marchello, E. (2003). I Processi Decisionali. Modelli, Esperienze, Applicazioni Nelle Organizzazioni Complesse. Milan: Franco Angeli.

68. McGaugh, J. (2000). Memory a Century of Consolidation. Science, (287), 248-251. http://science.sciencemag.org/content/287/ $\underline{5451 / 248 . f u l l}$
69. Meneghini Gobbetti, A. M., Pedon, A. (1988). Lezioni sulla Memoria. Verona: Libreria Universitaria Editrice.

70. Meneghini, A. M. (2002). Emozioni, Soddisfazione e Giudizi di Qualità del Cliente. Verona: Edizioni libreria cortina verona.

71. Ochsner, K., \& Gross, J. (2005). The Cognitive Control of Emotion. Trends in Cognitive Sciences,(9), 242-249.

http://www.sciencedirect.com/science/artic le/pii/S1364661305000902

72. Ortony, A., \& Turner, T. (1990). What's Basic About Basic Emotions?. Psychological Review, (3), 315-331. http://moodle.uws.ac.uk/pluginfile.php/10 9934/mod_resource/content/1/Week\%202 \%200rtony\%20and\%20Turner\%20(1990). pdf

73. Otnes, C., \& Beltramini, R. F. (1996). Gift Giving: A Research Anthology. Bowling Green: Bowling Green State University Popular Press.

74. Padoa Schioppa, C. (2007). Neuroscienze. Basi fisiologiche dei processi decisionali. Le scienze della vita, (2), 265-273. http://pcg.wustl.edu/padoaschioppalab/file s/Download/PadoaSchioppa\%202007b.PDF

75. Payne, J. W. (1976). Task Complexity and Contingent Processing in Decision Making: An Information Search and Protocol Analysis. Organizational Behavior and Human Performance, (16), 366-387.

http://web.unitn.it/files/download/12410/or ganizational_behavior_and_human_perfor mance.pdf

76. Plassman, H., \& Ramsøy, T. Z., \& Milosavljevic, M. (2012). Branding the Brain: A Critical Review and Outlook. Journal of Consumer Psychology, (22), 1836.

http://www.chilleesys.com/scp/assets/plass mann.pdf

77. Plutchik, R. (1980). A General Psychoevolutionary Theory of Emotion, in Plutchik, R., Kellerman, H. (ed.). Theory and Emotion. Orlando: Academic Press Inc.

78. Poletti, M. (2007). Brain Development, Decision-Making and Psychopathology in 
Adolescence. Italian Journal of Psychopathology, (13), 358-366.

http://www.jpsychopathol.it/issues/2007/v ol13-3/Poletti.pdf

79. Porcelli, A.J., \& Delgado, M.R. (2009). Acute Stress Modulates Risk Taking in Financial Decision Making. Psychological Science, (20), 278-283.

http://pss.sagepub.com/content/20/3/278.s hort

80. Preston, S. D., \& Buchanan, T. W., \& Stansfield, R. B., Bechara, A. (2007). Effects of Anticipatory Stress on Decision Making in a Gambling Task. Behavioral Neuroscience, (121), 257-263.

http://www-

personal.umich.edu/ prestos/Downloads/P restonetal2007_BN.pdf

81. Reimann, M., \& Bechara, A. (2010). The Somatic Marker Framework as a Neurological Theory of Decision-Making: Review, Conceptual Comparisons, and Future Neuroeconomics Research. Journal of Economic Psychology, (5), 767-776.

http://www.sciencedirect.com/science/artic le/pii/S0167487010000255

82. Robbins. T. W. (1997). Arousal Systems and Attentional Processes. Biological Psychology, (45), 57-71.

83. http://www.sciencedirect.com/science/artic le/pii/S0301051196052222

84. Rulke, D. L., \& Galaskiewicz, J. (2000). Distribution of Knowledge, Group Network Structure, and Group Performance. Management Science, (46), 612-625.

https://www.researchgate.net/publication/2 27447308

85. Russo, V. (2015). Neuromarketing, Comunicazione e Comportamenti di Consumo. Principi, Strumenti e Applicazioni nel Food and Wine. Milan: Franco Angeli.

86. Scherer, K. R., \& Schorr, A., \& Johnstone, T (2001). Appraisal Processes in Emotion: Theory, Methods, Research. New York: Oxford University Press.

87. Scherer, K. R. (2005). What Are Emotions? And How Can They Be
Measured?. Social Science Information, (44), 695-729. http://ssi.sagepub.com/content/44/4/695.fu 11.pdf + html

88. Sciarelli, M. (1996). Processo Decisionale e Valutazione Strategica. Padova: Cedam.

89. Seymour, B., 6 Dolan, R. (2008). Emotion, Decision Making, and the Amygdala. Cell Press, (58), 662-671.

http://www.sciencedirect.com/science/artic le/pii/S0896627308004558

90. Shani, Y., \& Zeelenberg, M. (2007). When and why do we want to know? How experienced regret promotes post-decision information search. Journal of Behavioral Decision Making, (20), 207-222. http://onlinelibrary.wiley.com/doi/10.1002 /bdm.550/epdf

91. Shani, Y., \& Tykocinski, O. \& Zeelenberg, M. (2008). When ignorance is not bliss: How feelings of discomfort promote the search for negative information. Journal of Economic Psychology, (29), 643-653.

92. https://encoller.tau.ac.il/sites/nihul_en.tau.ac.il/files/ RP_144_Shani.pdf

93. Simon, H. A. (1957). Models of Men. Social e Rational. New York: John Wiley $\&$ Sons.

94. Tiberi, E. (1979). La Paura della Civiltà Industriale. Naples: Guida Ed.

95. Tiberi, E. (1990). Misurazione della Noia Cronica. Milan: Giuffrè Editore.

96. Tosi, H., L., \& Pilati, M., \& Mero Neal, P., \& Rizzo, J. R. (2002). Comportamento Organizzativo. Persone, Gruppi e Organizzazioni. Milan: Egea.

97. Tucker, D. M., \& Williamson, P. A. (1984). Asymmetric Neural Control Systems in Human Self-Regulation. Psychological Review, (91), 185-215. http://psycnet.apa.org/index.cfm?fa=fullte xt.journal \&jcode $=$ rev\&vol $=91 \&$ issue $=2 \&$ page $=185 \&$ format $=$ PDF

98. van den Bos, R., \& Harteveld, M., \& Stoop, H. (2009). Stress And Decision Making in Humans: Performance is Related to Cortisol Reactivity, Albeit Differently in Men and Women. Psychoneuroendocrinology, (34), 14491458. 
DOI: $10.18535 /$ ijsrm/v5i9.18

http://www.sciencedirect.com/science/artic le/pii/S0306453009001486

99. Velásquez, J. (1998). Modeling EmotionBased Decision Making, in Cañamero, L. D. (Ed.), Emotional and Intelligent: the Tangled of Knot of Cognition. California: AAAI Press.

100. Vuilleumier, P., \& Richardson, M., \& Armony, J., \& Driver, J., \& Dolan, R. (2004). Distant Influences of Amygdala Lesion on Visual Cortical Activation During Emotional Face Processing. Nature Neuroscience, (7), 1271-1278. http://www.cns.nyu.edu/events/spf/SPF_pa pers/vuilleumier_etal_2004.pdf

101. Wanderlingh, E., \& Russo, D. (2008). Professione Psicologo. Milan: Edizione Alpha Test.

102. Zeelenberg, M., \& Nelissen, R. M., \& Breugelmans, S. M., \& Pieters, R. (2008). On Emotion Specificity in Decision Making: Why Feeling is for Doing. Judgment and Decision Making, (1), 18-27.

http://journal.sjdm.org/bb2/bb2.html 